\title{
How stigmatising language affects people in Australia who use tobacco, alcohol and other drugs
}

\section{Hester Wilson}

\section{Background}

Use of tobacco, alcohol and other drugs (TAOD) is common in Australia and can cause high morbidity and mortality. It is not uncommon for people who use TAOD to experience stigma when accessing healthcare, including general practice. Stigma communicated through words can affect people seeking help and undertaking treatment for their health issues. The language that clinicians use is an important factor that perpetuates stigma.

\section{Objective}

The aim of this article is to describe how spoken and written language can create stigma and how this affects a person's experience of care, which in turn can adversely affect health outcomes.

\section{Discussion}

Language matters, and this article suggests that clinicians consider how the language they use might affect the people they see. The use of personcentred language and specific language rather than labels may assist conversations and improve outcomes.
These words are razors to my wounded heart.

$$
\text { -William Shakespeare }{ }^{1}
$$

It is common for people who use tobacco, alcohol, and other drugs (TAOD) to experience stigma and discrimination..$^{2-4}$ Stigma can decrease willingness to disclose TAOD use and lead to decreased self-esteem, with significant adverse effects for the individual, their family and community..$^{5-7}$ Stigma contributes to the ongoing unmet need for TAOD treatment both in specialist and general practice settings in Australia ${ }^{8}$ and internationally. ${ }^{9}$ People who experience stigma have lower quality of life ${ }^{10}$ and can experience lower quality care with increased burden of illness. ${ }^{11}$ The sense of rejection that stigma engenders can itself lead to chronic stress and ill health, ${ }^{12}$ and those who are stigmatised are more likely to not adhere to or drop out of treatment, access treatment late or only seek treatment when very unwell. ${ }^{7}$

There is evidence that clinicians hold negative views towards people who use TAOD. ${ }^{3,13,14}$ Each clinician is a product of their culture and experience, and automatically characterises and labels every person they meet. Clinicians may not mean to stigmatise, but unconscious bias may lead to behaviours that can feel stigmatising. As a result, it is important for clinicians to reflect on the language they use when consulting with patients and discussing or recording information about TAOD use.

\section{Stigma and people who use TAOD} Stigma stereotypes and separates people through negative labelling, leading to rejection, exclusion and discrimination. ${ }^{15,16}$ It is a 'behaviour that favours one's group and intentionally or inadvertently harms another group. ${ }^{17}$ Stigma is harmful, distressing and marginalising. ${ }^{18}$ This experience can affect individuals, families and communities. The experience of stigma can lead to an internalisation of negative views of self as not worthy, less capable, less deserving and at fault. ${ }^{19}$

People who use TAOD are a stigmatised group. TAOD use, when seen as a personal choice, suggests self-induced adverse outcomes. In particular, people who use illicit drugs are collectively seen as unreliable and dangerous. ${ }^{12,20}$

Australia's public health policies (ie plain packaging, smoking bans) have made tobacco less socially acceptable, and smoking rates are now below $15 \% .{ }^{21,22}$ However, current smokers are more likely to have higher levels of dependence and experience complex health issues. For this group, these policies can feel stigmatising, contributing to continued smoking. ${ }^{23}$ 


\section{CASE 1}

Maria, aged 43 years, is a woman with severe endometriosis and chronic pelvic pain who was prescribed oxycodone $60 \mathrm{mg}$ daily. She became depressed after a bereavement and rapidly self-increased and started injecting her dose to manage her symptoms. She felt very ashamed, and this was compounded when a doctor told her she was a 'drug addict' and that they could not help her. She then saw a general practitioner (GP) who suggested that her chronic pain may have been complicated by opioid use disorder due to the medication. Together they developed a treatment plan. With her GP's support, staged supply from pharmacy, counselling and exercise, Maria's pain and mood improved markedly, and she was able to slowly decrease and cease the medication.

\section{CASE 2}

Mike, aged 43 years, has a family history of alcohol dependence. At the age of 32 years, after a series of setbacks, he started drinking heavily. He found that drinking daily helped him to cope but became concerned when he found that drinking alcohol stopped him from feeling shaky in the mornings. Mike asked a doctor for assistance, but was told, 'I can't help you; you just need to realise that you're an alcoholic and need willpower to stop'. Mike felt terrible about his behaviour and fearful that he was turning into his father. He tried unsuccessfully to change his drinking behaviour on his own. Some years later, he was admitted to hospital with acute pancreatitis. He was diagnosed with alcohol use disorder and went through alcohol detoxification in hospital. On discharge, at the urging of a friend, he saw a GP who assisted him with relapse prevention. Mike says, 'I felt hopeless and shameful, but my GP told me this was a serious health issue that, with support and treatment, could be successfully managed. With help I was able to stop drinking and stay stopped; I couldn't have done this without my GP.'

\section{What is stigmatising language?}

Language has power, and stigmatising language supports negative attitudes, leading to intentional and unintentional stigma and discrimination. Experiencing stigma creates sensitivity to the experience and can increase a person's stigma perception. ${ }^{10,24}$ Stigma is reinforced through language; it shapes people's views and understanding. Language affects the public discourse and perceptions of people who use TAOD and the concept of recovery. The way language is used in the media can adversely frame public perceptions and debate. ${ }^{25}$

Ethical healthcare is based on beneficence and non-maleficence and, at its best, allows patient autonomy and shared decision making. The use of non-stigmatising language can assist this. Broyles and colleagues suggest being aware of the following language attributes: ${ }^{26}$

- slang and idioms

- person-first language

- specific medical language

- recovery-promoting language.

\section{Slang and idioms}

The use of slang (ie informal words to describe the presentation) such as 'addict', 'junkie' or 'pothead', and idioms (ie phrases that describe a representation but are not deducible from the individual words) such as 'dirty urine' or 'getting clean' can perpetuate negative stereotypes. ${ }^{26}$ These words imply that TAOD use and addiction is a moral or personal failing, or a lack of willpower.9,27 They are 'verbal shorthands that are rich in metaphor and symbolism' ${ }^{26}$ and can implicitly or explicitly be judgemental and pejorative. ${ }^{28}$ Instead use 'person who uses drugs and/or alcohol', 'positive/negative urine' or 'person with lived experience of use'. ${ }^{29}$ People who use TAOD may use slang or idioms to label themselves. While these self-given labels may signify an oppressed group reclaiming identity, they may also be the product of internalised stigma - an expression of self-disgust. ${ }^{30}$ Gently questioning a person's self-described stigmatising language can help them to reframe experience and assist treatment engagement.

\section{Person-first language}

Person-first or person-centred language builds a sense of respect and humanity. Many doctors may recall being told as a medical student to go and see 'the AMI [acute myocardial infarction] in bed 2' or 'the pancreatitis in bed 4', or may have spoken about the 'diabetic' or 'hypertensive'. These titles suggest that the person is their illness, with a one-dimensional life without lived experience, expertise or personal agency. This can lead to disempowerment, making health-related change more difficult. ${ }^{26}$ In a study of clinicians, Kelly researched the difference between the phrases 'having a substance disorder' and 'substance abuser', and found that the term 'substance abuser' evoked more negative judgements. Clinicians saw 'substance abusers' as more reckless and culpable for their behaviour. ${ }^{9}$ Using language that is person-centred, such as 'a person with diabetes and hypertension' or 'a person with alcohol dependence or opioid use disorder', can help the person feel greater self-efficacy, enhancing treatment adherence. ${ }^{3}$

\section{Specific medical language}

The medical model of TAOD use disorders poses that risky and/or dependent TAOD use is not a moral failing or lack of willpower ${ }^{9,27}$ but is instead the result of a legitimate medical condition. It considers the impact of genetic, biological, psychological, socioeconomic, political and environmental factors that contribute to TAOD use. This medical framing allows the clinician and patient to see that TAOD use may be due to significant medical conditions and not moral failing. For example, the term 'person with a substance use disorder' describes a medical condition that will benefit from intervention and treatment, compared with 'addict', which describes innate qualities of a person and feels more stigmatising. Person-centred language promotes recovery and moves away from a focus on pathology towards healing. ${ }^{31}$

\section{Language that promotes recovery}

Recovery is about engaging in a life that has meaning and purpose for that 
person. ${ }^{32}$ For some it includes abstinence or lower-risk use, while for others it includes long-term medication. As a result, it can be helpful to suggest a range of treatments to assist people on their recovery journey. ${ }^{11}$ For example, long-term opioid agonist treatment (eg methadone or buprenorphine) for people with opioid dependency is a highly evidence-based treatment that results in good outcomes, with lower rates of blood-borne virus transmission, incarceration, overdose and all-cause mortality. ${ }^{33}$

Providing non-judgemental information about treatments to patients is more likely to assist them to make informed decisions about their healthcare.

Terms such as 'resistant' and 'non-compliant' tend not to assist clinicians to engage sympathetically with an individual's life and experience, and can be a barrier to people seeking care. There will be very good reasons why a person cannot agree with recommended treatment. Better word choices can include 'not in agreement with the treatment plan' or 'ambivalent about change at this point'. ${ }^{34}$

Recovery-focused language celebrates individual agency, self-efficacy and choice. ${ }^{34}$ While an individual's choice may not always align with medical advice, non-stigmatising language is likely to result in better long-term outcomes. Even if the patient does not agree with the treatment offered, they may be more inclined to seek help in the future.

Table 1 includes more suggested language options. This table was developed, with reference to international recommendations, in Australia by people who use TAOD and suggests the language they prefer.

\section{Setting boundaries}

There is no evidence that using stigmatising language assists people to change TAOD use and ample evidence that it can lead to adverse outcomes. Some people who use TAOD may exhibit challenging behaviours; as a result, it is understandable that clinicians who do not feel they have capacity, training and support may have negative attitudes towards people who use TAOD and be reluctant to assist. ${ }^{35}$ There are times when a clinician will need to express respectful concern for the patient's risky behaviours, for example, 'I am worried about your wellbeing and safety when you use heroin, can I assist you to change this behaviour with evidence-based treatments?' Another option is to say, 'I'm sorry, I cannot prescribe this medication because I don't think it safe; however, let's look at how I can assist you'. Using non-stigmatising language will help the patient to understand that refusal is due to a significant medical reason and not stigma. It may allow them to access appropriate care.

\section{Conclusion}

It is useful to question the impact that words can have on people who use TAOD. Non-stigmatising language allows the clinician and patient to better address the complex issues surrounding TAOD use, resulting in better engagement in treatment, improved treatment outcomes and decreased harms associated with TAOD use.

\section{Key points}

- Language has meaning.

- Patients are people with complex life stories; they are more than their diagnoses.

- Patients have individual preferences based on culture, language and environment.

- Internalised stigma affects the language patients use about themselves and others who use TAOD; this can adversely affect them, their health and wellbeing.

\section{Table 1. Language matters - a comparison of stigmatising language and person-centred language}

\begin{tabular}{ll}
\hline Try this & Instead of this \\
\hline Substance use, non-prescribed use & Abuse, misuse, problem use, non-compliant use \\
\hline Person who uses/injects drugs & Drug user/abuser \\
\hline Person with a dependence on ... & Addict, junkie, druggie, alcoholic \\
\hline Person experiencing drug dependence & Suffering from addiction, has a drug habit \\
\hline $\begin{array}{l}\text { Person who has stopped using drugs } \\
\text { Person with lived experience of drug } \\
\text { dependence }\end{array}$ & $\begin{array}{l}\text { Clean, sober, drug-free } \\
\text { Person disagrees }\end{array}$ \\
\hline
\end{tabular}

Treatment has not been effective/chooses Not engaged, non-compliant not to

\begin{tabular}{ll}
\hline Person's needs are not being met & Drug seeking, manipulative, splitting \\
\hline Currently using drugs & $\begin{array}{l}\text { Using again, fallen off the wagon, had } \\
\text { a setback }\end{array}$ \\
\hline No longer using drugs & Stayed clean, maintained recovery \\
\hline Positive/negative drug screen & Dirty/clean urine \\
\hline Used/unused syringe & Dirty/clean needle, dirties \\
\hline
\end{tabular}

Pharmacotherapy is treatment

Replacing one drug for another

Adapted with permission from Network of Alcohol and other Drugs Agencies and NSW Users and AIDS Association, Language matters, Woolloomooloo, NSW: NADA, 2018. 
- Stigmatising language can limit access and adherence to treatment and perpetuate ongoing risky or dependent use of TAOD.

- Non-stigmatising language assists with engagement, adherence and patient self-efficacy and consequently improves treatment outcomes.

\section{Author}

Hester Wilson BMed (Hons), FRACGP, FAChAM, $\mathrm{MMH}$, General Practitioner, Sydney, NSW; Staff Specialist in Addiction, Drug and Alcohol Services, South East Sydney Local Health District, NSW; Conjoint Lecturer and PhD candidate, School of Public Health and Community Medicine, University of New South Wales, NSW. hester.wilson@health.nsw.gov.au Competing interests: The author has no connections with the tobacco, alcohol or gaming industry. The author has received funding for consultancies and/or expert advisory panels with Indivior, Lundbeck, Mundipharma and Pfizer, all of which are unrelated to this article.

Funding: None.

Provenance and peer review: Not commissioned, externally peer reviewed.

\section{Acknowledgements}

Thanks to South Eastern Sydney Local Health District drug and alcohol service for their support of this work.

\section{References}

1. Shakespeare W. Titus Andronicus. Oxford, UK: Oxford University Press, 2008. Act I, Scene I.

2. Stafford J, Breen C. Australian drug trends 2016: Findings from the Illicit Drug Reporting System (IDRS). Australian Drug Trends Series No. 163. Sydney, NSW: National Drug and Alcohol Research Centre, UNSW, 2017.

3. van Boekel LC, Brouwers EP, van Weeghel J, Garretsen HF. Comparing stigmatising attitudes towards people with substance use disorders between the general public, GPs, mental health and addiction specialists and clients. Int J Soc Psychiatry 2015;61(6):539-49. doi: 10.1177/0020764014562051

4. Cooper S, Campbell G, Larance B, Murnion B, Nielsen S. Perceived stigma and social support in treatment for pharmaceutical opioid dependence. Drug Alcohol Rev 2018;37(2):262-72. doi: 10.1111/ dar.12601.

5. Weiss MG, Ramakrishna J, Somma D. Health-related stigma: Rethinking concepts and interventions. Psychol Health Med 2006;11(3):277-87. doi: 10.1080/13548500600595053.

6. Rocque R, Leanza Y. A systematic review of patients' experiences in communicating with primary care physicians: Intercultural encounters and a balance between vulnerability and integrity PLoS One 2015;10(10):e0139577. doi: 10.1371/ journal.pone.0139577.

7. Crapanzano KA, Hammarlund R, Ahmad B, Hunsinge N, Kullar R. The association between perceived stigma and substance use disorder treatment outcomes: A review. Subst Abuse Rehabil 2018;10:1-12. doi: 10.2147/SAR.S183252.
8. Ritter A, Berends L, Chalmers J, Hull P, Lancaster K, Gomez M. New horizons: The review of alcohol and other drug treatment services in Australia - Final Report. Randwick, NSW: NDARC, 2014.

9. Kelly JF, Westerhoff CM. Does it matter how we refer to individuals with substance-related conditions? A randomized study of two commonly used terms. Int J Drug Policy 2010;21(3):202-07. doi: 10.1016/j.drugpo.2009.10.010.

10. Earnshaw VA, Quinn DM. The impact of stigma in healthcare on people living with chronic illnesses. J Health Psychol 2012;17(2):157-68. doi: 10.1177/1359105311414952.

11. Gordon A, Broyles LM. A physician-centered approach to addiction identification and treatment misses the opportunity for interdisciplinary solutions. Subst Abus 2014;35(2):108-09. doi: 10.1080/08897077.2014.898976.

12. Ahern J, Stuber J, Galea S. Stigma, discrimination and the health of illicit drug users. Drug Alcohol Depend 2007;88(2-3):188-96. doi: 10.1016/j. drugalcdep.2006.10.014.

13. Lloyd C. The stigmatization of problem drug users: A narrative literature review. Drugs (Abingdon Engl) 2013;20(2):85-95. doi: 10.3109/09687637.2012.743506.

14. Merrill JO, Rhodes LA, Deyo RA, Marlatt GA, Bradley KA. Mutual mistrust in the medical care of drug users: The keys to the 'narc' cabinet. J Gen Intern Med 2002;17(5):327-33. doi: 10.1007/ s11606-002-0034-5.

15. Link BG, Phelan JC. Conceptualizing stigma. Annu Rev Sociol 2001;27:363-85. doi: 10.1146/annurev. soc.27.1.363.

16. Sartorius N. Lessons from a 10-year global programme against stigma and discrimination because of an illness. Psychol Health Med 2006;11(3):383-88. doi: 10.1080/13548500600595418.

17. Al Ramiah A, Hewstone M. Discrimination: Conditions, consequences, and 'cures'. In: Huddy L, Sears DO, Levy JS. Oxford handbook of political psychology. Oxford, UK: Oxford University Press, 2013.

18. Corrigan PW, Watson AC. Understanding the impact of stigma on people with mental illness. World Psychiatry 2002;1(1):16-20.

19. von Hippel C, Brener L, Horwitz R. Implicit and explicit internalized stigma: Relationship with risky behaviors, psychosocial functioning and healthcare access among people who inject drugs. Addict Behav 2018;76:305-11. doi: 10.1016/j. addbeh.2017.08.036.

20. Room R, Rehm J, Trotter RT, et al. Cross-cultural views on stigma, valuation, parity and societal values towards disability. In: Disability and culture: Universalism and diversity. Hogrefe \& Huber, 2001; p. 247-91.

21. Bayer R. Stigma and the ethics of public health: Not can we but should we. Soc Sci Med 200867(3):463-72. doi: 10.1016/j. socscimed.2008.03.017

22. Australian Institute of Health and Welfare. National drug strategy household survey 2016 : Detailed findings. Drug Statistics series no. 31 Cat. no. PHE 214. Canberra: AIHW, 2017.

23. Stuber J, Galea S, Link BG. Smoking and the emergence of a stigmatized social status. Soc Sci Med 2008;67(3):420-30. doi: 10.1016/j. socscimed.2008.03.010.

24. Tran N, Baggio S, Dawson A, et al. Words matter: A call for humanizing and respectful language to describe people who experience incarceration. BMC Int Health Hum Rights 2018;18(1):41. doi: 10.1186/s12914-018-0180-4.

25. Szalavitz M. Why we should say someone is a 'person with an addiction,' not an addict. NPR. Available at https://www.npr.org/ sections/health-shots/2017/06/11/531931490/ change-from-addict-to-person-with-an-addictionis-long-overdue [Accessed 11 June 2017].

26. Broyles $L$, Binswanger $I A$, Jenkins JA, et al. Confronting inadvertent stigma and pejorative language in addiction scholarship: A recognition and response. Subst Abus 2014;35(3):217-21. doi: 10.1080/08897077.2014.930372.

27. Olsen Y, Alford D, Horton NJ, Saitz R. Addressing smoking cessation in methadone programs. J Addict Dis 2005;24(2):33-48. doi: 10.1300/ J069v24n02_04.

28. Manderson D. Metamorphoses: Clashing symbols in the social construction of drugs. J Drug Issues 1995;25(4):799-816. doi: 10.1177/002204269502500410.

29. Alcohol and Drug Foundation. The power of words. Having alcohol and other drug conversations: A practical guide. North Melbourne, Vic: ADF, 2019.

30. McGaffin BJ, Lyons GC, Deane FP. Self-forgiveness, shame, and guilt in recovery from drug and alcohol problems. Subst Abus 2013;34(4):396-404. doi: 10.1080/08897077.2013.781564.

31. White $W$. The rhetoric of recovery advocacy: An essay on the power of language. In: Let's go make some history: Chronicles of the new addictive recovery advocacy movement. Washington: Johnson Institute, 2006; p. 37-76.

32. Dale-Perera A. Recovery, reintegration, abstinence, harm reduction: The role of different goals within drug treatment in the European context. Lisbon: EMCDDA, 2017.

33. World Health Organization. Guidelines for the psychosocially assisted pharmacological treatment of opioid dependence. Geneva: WHO, 2009.

34. Harris J, Felman K. Guide to the use of recovery-oriented language in service planning, documentation, and correspondence. Pittsburgh, PA: Mental Health America Allegheny County, 2012.

35. Miller ER, Ramsey IJ, Tran LT, et al. How Australian general practitioners engage in discussions about alcohol with their patients: A cross-sectional study. BMJ Open 2016;6(12):e013921. doi: 10.1136/ bmjopen-2016-013921. 